\title{
Las Indias y la tratadística militar hispana de los siglos XVI y XVII
}

\author{
Antonio Espino López \\ Departamento de Historia Moderna y Contemporánea \\ Universidad Autónoma de Barcelona
}

En nuestro trabajo hemos pretendido vincular un aspecto muy poco tratado por parte de la historiografía hispana, la tratadística militar, con el ámbito americano. Hemos defendido que la forma de hacer la guerra de los hispanos en América, centrándonos en el caso de la conquista de México, siguió las pautas marcadas por el Gran Capitán en las Guerras de Italia. Es decir, se impuso el nuevo modelo de escuadrón y fue este factor, y no tanto la superioridad del arma de fuego o el uso de la caballería, lo que dio ventaja real a la hueste indiana sobre los ejércitos indios. En segundo lugar, se han tratado tres ejemplos de tratadística militar hispana: uno de los primeros impresos en México, el de D. García de Palacio; un segundo que versa sobre la guerra en América, el de B. de Vargas Machuca y un tercero, ejemplo del siglo XVII, redactado en la Península, pero también impreso finalmente en las Indias, el de A. de Heredia Estupiñán.

En las siguientes líneas vamos a intentar vincular un aspecto muy poco tratado por parte de la historiografía hispana, la tratadística militar, con el ámbito americano. En primer lugar, nos hemos interesado por la forma de hacer la guerra de los hispanos en América, centrándonos en el caso de la conquista de México, ${ }^{1}$ para intentar demostrar cómo el nuevo modelo de escuadrón, puesto en práctica en las guerras de Italia por Gonzalo Fernández de Córdoba, el Gran Capitán, por primera vez, se impuso entre las huestes indianas. ${ }^{2}$ A nuestro juicio, fue este factor, y no tanto el uso de las armas de fuego o de la caballería, el que marcó la diferencia sobre las tácticas indias durante sus enfrentamientos. En segundo lugar, y tras constatar el hecho de que un cierto número de tratadistas militares hispanos de los siglos XVI y XVII gozaron de algún tipo de cargo en las Indias, mostraremos algu-

1 Molina, Miguel: "El soldado-cronista y su impresión del mundo indígena (el caso de Nueva España)", Anuario de Estudios Americanos, XVL, Sevilla, 1984, págs. 291-313. Trabajo interesante, pero que apenas hace referencia al tema que tratamos nosotros.

2 Sobre la hueste indiana véanse: sobre sus antecedentes bajomedievales el trabajo de Ramos, Demetrio: Determinantes formativos de la "hueste" indiana y su origen modélico, Santiago de Chile, 1965. García Gallo, Alfonso: "El servicio militar en Indias", en Estudios de Historia del derecho indiano, Madrid, 1972, págs. 745-812. Gómez Pérez, Carmen: "Las huestes indianas" en Navarro García, uis (coord.): Historia de las Américas, Vol. I, Madrid, 1991, págs. 447-469. Navarro García, Luis: "El arte de la guerra en la conquista de América", en La organización militar en los siglos XV y XVI. Actas de las II Jornadas Nacionales de Historia Militar, Málaga, 1993, págs. 483-492. 
nos ejemplos — sólo tres, por un obvio problema de extensión — de tratadística militar escrita e impresa en —o sobre- América y su relación con las obras producidas por entonces en los territorios hispánicos de Europa.

\section{Los héroes de la Antigüedad y los conquistadores}

En el libro IX de La razón de Estado (1589), G. Botero reclamaba al príncipe que hiciera escribir las guerras que hubiese auspiciado, porque, de ese modo, las proezas realizadas serían conocidas por los demás y actuarían como un estímulo. Para Botero, "en esto han faltado grandemente los castellanos, porque habiendo hecho cosas dignísimas de memoria, recorrido tantos mares, descubierto tantas islas y continentes, sojuzgado tantos países y, por último, adquirido un mundo nuevo, no se han tomado el cuidado de que estas empresas, que superan en mucho a las de los griegos y macedonios, fuesen escritas por personas que supiesen hacerlo". ${ }^{3}$

Ciertamente, muy pocos autores —entre ellos los que habían estado destinados en las Indias - iban a tener como referentes militares a los conquistadores. Si atendemos a lo que nos dicen los tratadistas, el militar debe leer libros de Historia para extraer de ellos un provecho. ${ }^{4} \mathrm{Si}$ tal provecho es de aplicación inmediata, en las campañas europeas - o, como mucho, contra los infieles en el Mediterráneo- del momento, difícilmente el conocimiento de la realidad de la guerra en América iba a suponer una ventaja táctica o estratégica para el oficial hispano en sus guerras. Está comúnmente aceptado que la hueste indiana hubo de adaptarse al tipo de guerra que se hacía en América - y la obra de Vargas Machuca es el mejor ejemplo-, y no al revés. Por lo tanto, era muy poco lo que se podía aprender, y consecuentemente aplicar, de las campañas de los conquistadores. Además, a la corona no podía interesarle que sus mejores soldados marchasen a América. Para B. Escalante, su obra Diálogos del arte militar (Bruselas, 1588) tenía como destinatarios los oficiales sin experiencia, para que "se

3 Botero, Giovanni: La razón de Estado y otros escritos, traducción y edición de L. de Stefano y M. García-Pelayo, Caracas, 1962, pág. 175.

4 Juan de Santa María pensaba que la Historia, junto con la experiencia, era una de las "fuentes de la humana prudencia. Pues es cierto, que por los efectos de los casos passados, podemos conocer quales fueron las causas dellos, para tener en otras tales los mismos sucessos", Tratado de República y policía christiana para reyes y príncipes y para los que en el govierno tienen sus vezes (Madrid, 1615), citado por J.A. Fernández Santamaría, estudio preliminar de Alamos de Barrientos, Baltasar: Aforismos al tácito español, Madrid, 1987, págs. LXI-LXII. 
hagan pláticos en breve tiempo, ya que en nuestra España falta de todo punto esta doctrina", y, significativamente, apunta que los más necesitados, por inexpertos, eran los oficiales que se enviaban a Ultramar.

Por otro lado, ¿qué había de glorioso u honrado —en el sentido de la época - en una lucha contra la humanidad bárbara americana, en la pugna contra guerreros como aquellos, cuando en Europa se luchaba contra los herejes, contra la tradicional enemiga Francia o, mejor aún, contra los infieles turcos y berberiscos? En las guerras del Viejo Mundo se peleaba por Dios y por el rey, por el honor personal y por unas recompensas materiales. En América también, en principio, pero, sobre todo, se peleará por los compañeros y por uno mismo, se luchará por sobrevivir o para no seguir viviendo como hasta entonces: por la parte correspondiente de un botín. En las Indias no se aspira a hacer carrera militar, como mucho a invertir el botín logrado en planificar una nueva conquista y actuar como un caudillo - como significativamente llamaba a los jefes militares B. Vargas Machuca-. Los cargos políticos más relevantes están reservados a los peninsulares. Los conocimientos aportados por esta realidad eran inaplicables en Europa. Por otro lado, ¿cuántos soldados indianos regresaron a luchar a Europa?

El militar hispano, como de todos es conocido, durante el siglo XVI aprenderá su oficio en Italia o Flandes, preferentemente. En el Seiscientos lo mismo, con el añadido que, desde 1635, también se luchará en territorio peninsular. América quedaba fuera de este circuito de aprendizaje y promoción militar. Sin duda, G. Botero tenía razón en lo que decía. ${ }^{5}$ La Guerra de los Países Bajos fue ampliamente utilizada por los tratadistas hispanos de finales del Quinientos y, sobre todo, del Seiscientos como fuente de conocimientos militares que era interesante transmitir. La mejor prueba son las muchas obras que aparecieron - y sus contenidos-, escritas en algunas ocasiones por soldados que habían vivido los hechos que relataban. ${ }^{6}$ En las

5 Botero decía acerca de la Historia: “es... el más bello espectáculo que se pueda imaginar; allí, a costa de otros, el hombre aprende lo que le conviene; allí se ven los naufragios sin horror, las guerras sin peligro...; allí se vislumbran los principios, medios y fines y los motivos del crecimiento y ruina de los Imperios; allí se aprenden las causas por las cuales unos príncipes reinan tranquila y otros penosamente; unos florecen con el arte de la paz, otros con el valor de las armas"; La razón de Estado..., pág. 111.

6 Sin ánimo de ser exhaustivos, no debemos olvidar a Mendoza, Bernardino de: Comentarios de lo sucedido en las guerras de los Países Bajos desde el año de 1567 hasta el de 1577, Madrid, 1592; años antes había aparecido la de Cornejo, Pedro: Sumario de las guerras civiles, y causas de la rebelión de Flandes, Lyon, 1577, y Origen de la civil disensión de Flandes, Turín, 1580. Trillo, Antonio: Historia de la rebelión y guerras de Flandes, con unos muy importantes y provechosos discursos en materia de guerra y estado..., Madrid, 1592, incorpora, como se observa en el título, no 
obras dedicadas a las diferentes conquistas del territorio americano también se podían extraer lecciones válidas para los militares, pero difícilmente aplicables a la guerra en Europa.

En el caso americano, más que la táctica o la estrategia empleadas, lo que quizás interesó más fue la figura de un héroe hispano - F. Pizarro y, sobre todo, H. Cortés - asimilable a los de la Antigüedad. En realidad, en las Indias se produjo una situación que, salvando las distancias, recordaba algunas de las campañas gloriosas de la Antigüedad: un número muy reducido de soldados — con mucha más infantería que caballería—, pero hábiles y disciplinados guerreros, se impusieron a ejércitos poderosos. Es el caso de Alejandro Magno en sus campañas asiáticas; el de Aníbal y su larga marcha hacia Italia y las posteriores luchas en territorio hostil; también es el caso de César en sus campañas de las Galias, Britania o Helvetia; o el de la retirada de los mercenarios griegos que habían ayudado a Ciro el Menor en su lucha fratricida, tan magníficamente relatada por Jenofonte. Con razón Giovanni Botero había visto la similitud. Algunos autores hispanos también la percibieron.

Cuando un autor como J. Castillo de Bovadilla a fines del Quinientos escribió su Política para corregidores y señores de vasallos en tiempo de paz y guerra (Madrid, 1597), ${ }^{7}$ al plantearse la preparación de la guerra, como en el caso de tantos otros tratadistas, asumió la idea de que pequeños ejércitos bien disciplinados se imponían a las grandes masas mal organizadas y de escaso espíritu militar. Lo interesante es que los ejemplos aducidos por Castillo de Bovadilla no sólo se refieren a la Antigüedad, sino también a la actuación de H. Cortés y F. Pizarro en América. El padre Alonso de Andrade publicó El buen soldado católico en Madrid en 1642. La idea que el autor quería transmitir era muy simple: el soldado debía ser un buen cristiano y de esa forma alcanzaría tanto la victoria militar como la gloria

sólo lo particular, sino también un conocimiento más general. Y en el Seiscientos, con el reinicio de las hostilidades contra los rebeldes holandeses en el marco de la Guerra de los Treinta Años, se publicó mucho sobre el tema. El maestre de campo F. Verdugo vio impreso su Comentario de la guerra en Frisa (Nápoles, 1610), que abarcaba de 1581 a 1594. El contador del Ejército de Flandes Antonio Carnero vio publicada su Historia de las Guerras Civiles que ha avido en los Estados de Flandes des del Año 1559 hasta el de 1609 y las causas de la rebellion de dichos Estados (Bruselas, J. Meerbeque, 1625, Fol.), un trabajo importante con 565 páginas. También Francisco Lanario, tratadista militar, prolongó su obra hasta la Tregua de los Doce Años: Las guerras de Flandes, desde el año 1559 hasta el de 1609 (Madrid, L. Sánchez, 1623). Las guerras de los Estados Baxos desde el 1588 hasta el 1599, de don Carlos Coloma, a veces se atribuye a Diego de Ibarra, a quien estaba dedicada (Barcelona, 1627).

7 La obra tuvo un gran éxito: fue reeditada en Medina del Campo (1608), Barcelona (1616 y 1624), Madrid (1649) y en Amsterdam (1704). Utilizamos la edición facsímil de esta última edición, Madrid, Instituto de Estudios de Administración Local, 1978, 2 Vols. 
eterna. Cuando lo cree conveniente, Andrade introduce ejemplos de cómo los grandes soldados podían ser también virtuosos; una cosa y otra no están reñidas. Los soldados citados son Alejandro Magno, Carlomagno, Alarico, Escipión, Hernán Cortés y el Cid. Es notable que el conquistador extremeño esté ya en pie de igualdad con la élite militar universal. El padre Juan B. Gil de Velasco vio impreso su Católico y marcial modelo de prudentes y valerosos soldados en Madrid (1650). El rastro de sus lecturas, y de las opiniones clásicas, se observa cuando este autor ensalza como ejército disciplinado el de los romanos - sin olvidar el Ejército de Flandes en la época del duque de Alba - y recuperando la máxima, extraída del Epitoma rei militaris de Vegecio, de que unos pocos, pero disciplinados, son superiores a muchos. Para demostrar esto último no necesita recurrir a ejemplos de la Antigüedad cuando cuenta con las hazañas de un H. Cortés o de un F. Pizarro. Parece como si, poco a poco, estas actuaciones fueran calando en la conciencia de los autores hispanos y se terminó por asimilar sus hechos de armas con los protagonizados por los greco-latinos, el Gran Capitán en Italia - el mayor héroe militar hispano en el siglo XVI sin discusión-, el duque de Alba y sus oficiales - Sancho de Londoño, F. de Valdés, B. de Mendoza y otros- en Flandes, o la victoria cristiana en Lepanto.

\section{El caso de la conquista de México}

Ahora bien, estos dos últimos ejemplos corresponden a dos autores religiosos que escriben cuando las rebeliones de Portugal y Cataluña, además de la napolitana de 1647, pusieron en jaque a la Monarquía Hispánica mientras ésta se enfrentaba a su secular enemiga, Francia. Eran años en los que había que recurrir a todos los héroes disponibles. ¿Es casualidad que, en los momentos de máxima decadencia del reinado de Carlos II, un autor como Antonio de Solís se decidiera a escribir — con mucho éxito, por cierto- - sobre la hazaña de H. Cortés y los suyos? Secretario regio y cronista mayor de Indias, Antonio de Solís (1610-1686) publicó su Historia de la conquista de México en 1684, el mismo año en el que Luis XIV ocupó Luxemburgo, fortaleza considerada inexpugnable. Refiriéndose a la conquista de México, Solís utiliza unas palabras, en su dedicatoria a Carlos II, que casi podrían aplicarse al caso luxemburgués: "siendo una empresa de inauditas circunstancias, que admiró entonces al mundo, y dura, sin perder la novedad, en la memoria de los hombres". Y más adelante dice: "Los 
sucessos de que se compone su narración, dan motivos a diferentes Reflexiones Políticas, y Militares: una conquista que importó a V. Mag. no menos que un Imperio; y se consiguió, dexando a la posteridad varios exemplos de lo que pueden contra las dificultades el valor, y el entendimiento". En la aprobación de Nicolás Antonio podemos leer: "Llenos están los libros de las proezas de Hernán Cortés, y de esta su empressa, no inferior, a mi parecer, por el poco número de su gente, por las dificultades que se le opusieron, por las peligrosíssimas batallas... no inferior, digo, a las de Alexandro, a las de César, a las de Belisario y a las de tantos Reyes de nuestra España". ${ }^{8}$

Según Solís, la conquista del territorio americano se realizó gracias a empresas simultáneas lideradas por "diversos Capitanes de mucho valor, pero de pocas señas: llevaban a su cargo unas Tropas de Soldados, que se llamaban Exércitos, y no sin alguna propiedad, por lo que intentaban, y por lo que conseguían". De entrada, la naturaleza de estas agrupaciones - y las cualidades de sus jefes - las hacían poco aptas para un uso ejemplificador. Sus adversarios sólo destacaban por el número y por algunas de sus características no ofensivas: se pintaban para parecer horribles al enemigo - una práctica que le recuerda a Solís la descripción que de los Arios de la Germania hizo Tácito- y utilizaban el griterío en el momento del ataque - que no es costumbre bárbara, apunta Solís, pues los romanos en sus batallas también lo hacían. Lo interesante es que, en el siglo XVI algunos tratadistas exigirán el silencio en el combate para que se oyeran las órdenes: como en esta época la mayoría de las agrupaciones militares eran multinacionales, y la premura de la acción militar obligaba a que las órdenes se cumplieran inmediatamente, éstas se transmitían mediante pífanos y tambores, de modo que se alababa el combate lo más silencioso posible. Lo cual no quiere decir que el estruendo de la artillería no fuese, en el ámbito americano, un arma psicológica.

Pero la descripción que realiza A. de Solís sobre la forma de combatir de los indios no deja dudas: cuando analiza sus armas, tanto defensivas como ofensivas, cuida mucho en resaltar que el acero no estaba presente. Sus protecciones - los que las llevaban- eran de algodón, de conchas de tortuga, de madera... Lo más importante es su análisis del escuadrón: los formaban "amontonando, más que distribuyendo la gente"; los capitanes "guiaban, pero apenas governaban su gente; porque en llegando la ocasión,

8 Solís, Antonio de: Historia de la conquista de México, cito por la edición de Madrid, J. García Lanza, 1758. 
mandaba la ira, y a veces el miedo: batallas de muchedumbre, donde se llegaba con igual ímpetu al acometimiento, que a la fuga". ${ }^{9}$ Frente a tales disposiciones, A. Solís relata las medidas de H. Cortés en Tabasco; siguiendo el modelo literario utilizado por Tito Livio, Tácito o César, el autor se centra en la figura del personaje más importante y describe su forma de actuar: Cortés, tras animar a sus hombres — pues debían enfrentarse a 40.000 indios-, los colocó tras una altura, para que les cubriera las espaldas, situó la artillería en un lugar desde donde barriese al contrario, cosa fácil al acercarse éste apelotonado, y dispuso a su caballería — tan sólo quince caballos- para que embistiese de través al enemigo (Libro I, capítulo 19). Más adelante, cuando se relata el primer contacto belicoso con los tlaxcaltecas, A. de Solís se contradice al afirmar la diligencia con la que éstos maniobraron para intentar cercar la hueste de Cortés, una vez había sido atraído a terreno llano. En esta ocasión, "fue necesario dar quatro frentes al Esquadrón, ${ }^{10}$ y cuidar antes de resistir que de ofender, supliendo con la unión y la buena ordenanza, la desigualdad del número" (Libro II, capítulo 17). Era ésta, y no las armas de fuego o la caballería, la principal arma de la que disponían los españoles. No en vano Cortés había arengado a sus hombres en la isla de Cozumel diciéndoles, entre otras cosas, "pocos somos; pero la unión multiplica los Exércitos", sobre todo si un sólo general impartía las órdenes. En esta ocasión, A. de Solís procura imitar más que nunca el estilo de César en sus Comentarios. F. López de Gómara también reitera una y otra vez la importancia del escuadrón hispano "bien concertado", es decir, perfectamente formado, colocando en medio tanto el bagaje - fardaje lo llama Gómara- y la artillería para protegerlos mientras se marchaba. Si bien en terreno llano tanto la artillería como la caballería podían obrar milagros contra el enemigo, lo más difícil era avanzar constantemente en un buen orden y poder presentar batalla en cualquier momento. ${ }^{11}$ Uno de los tratadistas militares hispánicos que mejor explicaron la tradicional táctica del escuadrón fue Carlos Bonieres, barón de Auchy; en su Arte militar deducido

9 Ibídem, Tomo I, págs. 5 y 111-117. En cambio, un contemporáneo de los hechos, Francisco López de Gómara, si hablará de que los indios, en la batalla de Cintla, formaban escuadrones, caminaban "muy en ordenanza" y sabían escoger el terreno donde pelear, de modo que "no eran bárbaros ni mal entendidos en guerra". López de Gómara, Francisco: Historia de la conquista de México, Caracas, 1979, pág. 37.

10 Se trata del escuadrón denominado "cuadrado de gente" con el cual, con idéntico número de hombres de frente que de hileras de fondo, se podía repeler un ataque que viniese por la vanguardia, la retaguardia o cualquiera de los dos flancos. Todos los tratadistas militares explicaban en sus obras este tipo de agrupación.

11 López de Gómara: Historia de la conquista..., págs. 78-80. 
de sus principios fundamentales (Zaragoza, 1644) dirá: "una buena orden alegra a los amigos, espanta a los enemigos, asegura al Exército, facilita sus movimientos i la distribución de las órdenes, que dan los cabos; de modo que sin ruido, sin embaraço, manda el General lo que de mano en mano, de oído en oído, llega al menor soldado; i es la orden, la que puede hazer un exército invencible, como la falta della, la que ha hecho perecer algunos de los más poderosos" (págs. 102-103).

Volviendo a los cronistas, un conquistador como Bernal Díaz del Castillo en su Historia verdadera de la conquista de Nueva España (Madrid, 1632) no desea emparejarse con César en su estilo literario, sino en sus hazañas bélicas: "Me hallé en más batallas y reencuentros de guerra que dicen los escritores que se halló Julio César, y para escribir sus hechos tuvo extremados cronistas y no se contentó de lo que de él escribieron, que el mismo Julio César por su mano hizo memoria en sus Comentarios de todo lo que por su persona pasó". Para criticar a aquellos que proclamaban las matanzas de indios por parte hispana, Díaz del Castillo no dudaba en resaltar el corto número de gente que participó, cuando además los indios contaban con "sus armas de algodón, que les cubrían el cuerpo, y arcos, saetas, rodelas, lanzas grandes, espadas de navajas como de a dos manos, que cortan más que nuestras espadas, y muy denodados guerreros" (Capítulo XVIII). Es decir, las fuerzas estaban muy igualadas. Cuando en el capítulo XXVI trata Bernal Díaz del alarde de tropas que hace Cortés en la isla de Cozumel, destaca el cuidado que se ponía en las armas, especialmente la artillería, significativamente al mando de Francisco de Orozco, "que había sido soldado en Italia", mientras que las ballestas debían estar en perfecto uso y con repuestos. ${ }^{12}$ También se comenta cómo la marcha de Cempoala hacia Tlaxcala se emprendió con todos los hombres armados día y noche - "con ellas dormíamos e caminábamos"-, mientras doscientos tamemes se encargaban de la artillería, y se enviaban exploradores por

12 Una lista de soldados veteranos de las guerras europeas en Castrillo, Francisco: El soldado de la conquista, Madrid, 1992, págs. 204-206. Aunque no todos los cronistas estarán de acuerdo, como veremos, lo cierto es que se valoraba la experiencia militar adquirida en Europa, es decir, en Italia, especialmente a la hora de formar los escuadrones. El Inca Garcilaso de la Vega relata que, una vez iniciadas las Guerras Civiles del Perú, y habiéndose puesto las tropas de Vaca de Castro en orden de batalla, Diego de Almagro (hijo) hizo lo propio con las suyas, dispuesto para el combate, pero delegando tal menester en su sargento mayor, Pedro Suárez, "que había sido soldado plático en Italia y sabía bien de milicia, reconociendo la ventaja que en el sitio tenía a sus contrarios, formó luego su escuadrón". La batalla de Chupas (1542) fue una derrota almagrista porque las órdenes de Suárez — sin olvidar la traición del jefe artillero Pedro de Candía- no se cumplieron. El Inca Garcilaso de la Vega: Comentarios reales, Tomo II, Ginebra, 1974, págs. 129-137. 
delante (Capítulo LXI). En la segunda batalla con los tlaxcaltecas, Díaz del Castillo coincide con Solís en la gravedad del momento, cuando "medio desbaratado nuestro escuadrón, que no aprovechaban voces de Cortés ni de otros capitanes para que tornásemos a cerrar; tanto número de indios cargó entonces sobre nosotros, que milagrosamente, a puras estocadas, les hicimos que nos diesen lugar, con que volvimos a ponernos en concierto" (Capítulo LXV). De nuevo, la indisciplina india a la hora de formar escuadrones - además de sus diferencias internas- se nos presenta como su principal debilidad militar.

Mucho más peligroso será el combate en Tenochtitlán una vez había sido apresado Moctezuma, derrotado e incorporado a la hueste cortesiana el ejército de Narváez, y Pedro de Alvarado, con sus excesos, hubiese levantado a los mexicas. Bernal Díaz, que recuerda cómo apenas dormían, siempre armados y con los caballos enfrenados, situación que indica unas condiciones de vida de las tropas más duras que en Europa (Capítulo CVIII) - y sin contar la presión psicológica de estar rodeados por una masa humana tan enorme-, explica cómo la masa de indios, que peleaban sin temor a las bajas que les causaban, estuvo a punto de exterminarlos. Es importantísima la siguiente cita: "E no sé yo para qué lo escribo ansí tan tibiamente, porque unos tres o cuatro soldados que se habían hallado en Italia, que allí estaban con nosotros, juraron muchas veces a Dios que guerras tan bravosas jamás habían visto en algunas que se habían hallado entre cristianos contra la artillería del rey de Francia, ni del gran turco; ni tanta gente como aquellos indios, que con tanto ánimo cerrar los escuadrones vieron" (Capítulo CXXVI). ${ }^{13}$

Tras la "Noche triste", cuando H. Cortés hubo recuperado fuerzas y apostó por sitiar la ciudad de Tenochtitlán, se fue acercando a dicho lugar con todas las prevenciones posibles. Bernal Díaz repite constantemente cómo se enviaban avanzadillas para explorar el terreno que iba a cruzar el

13 El cronista Fernández de Oviedo se burlaba bastante de la preeminencia adquirida por los veteranos de Italia. Pensaba que, entre las cualidades del soldado, debía estar presente el ser sencillo, recatado y no presumido. No faltaba el que alardeaba de haber participado en alguna de las grandes batallas en suelo italiano: "si os diçe que se halló en la [batalla] de Ravena, no curéis dél si es español, pues que quedó vivo y no fue preso; e si estuvo en la de Pavía, tampoco; o en el saco de Génova o de Roma, mucho menos, pues no quedó rico, y si lo fue, lo jugó o ha perdido: no fiéis dél”. Además, la realidad americana era muy diferente a las "comodidades" que los soldados hallaban en Italia; por otro lado, la esperanza de hallar un botín hacía a todos los hombres leales y fieles, situación que podía cambiar rápidamente en caso de no hallarlo y, por lo tanto, momento en el que se debían valorar las virtudes morales del soldado. Véase, Gerbi, Antonello: La naturaleza de las Indias Nuevas, México, 1992, págs. 382-383. 
ejército cortesiano y cómo éste caminaba siempre "con mucho concierto, como lo teníamos de costumbre", precaución que aumentó al entrar en territorio mexicano: "íbamos más recatados, nuestra artillería puesta con mucho concierto y ballesteros y escopeteros" (Capítulo CXXXVII). H. Cortés, tras proveerse de saetas y de munición para sus bocas de fuego, hizo un alarde en Texcoco repartiendo soldados entre los trece bergantines construidos y dividiendo el resto de sus tropas en tres grupos con sus respectivos capitanes para que cercasen Tenochtitlán. Las ordenanzas pregonadas entonces, además de reflejar las medidas habituales en tales casos - evitar las blasfemias, no abandonar el puesto encomendado o dormirse en las guardias-, incluyen algunas otras acordes con las circunstancias: evitar cualquier enfrentamiento con los aliados indios, estar siempre con las armas a punto y preparados, evitar alardear de habilidad y destreza poniendo en peligro los caballos y las armas de fuego... (Capítulo CXLVIII).

Una vez iniciado el sitio, Díaz del Castillo comenta cómo hubieron de cambiar la forma de combatir a los mexica en el interior de su ciudad, pero dejando muy claro que su única virtud era su número y la mayor dificultad la estructura urbana de Tenochtitlán. Significativamente, Bernal Díaz se refiere a los mexica como "gentecilla", mientras que los aliados tlaxcaltecas son definidos como "varones", aunque se contradice en cuanto habla del tesón defensivo de los primeros y las grandes dificultades que tuvieron para vencerles, con combates tan constantes que, en un momento dado de la narración, para no ser tan prolijo, Bernal Díaz alega que un relato pormenorizado de lo sucedido haría que su obra "parescería a los libros de Amadís o Caballerías".

Tras describir algunas maniobras de una y otra parte para buscar nuevos aliados y algún intento de Cortés por negociar la paz, Bernal Díaz comenta cómo se le dio crédito a un soldado, Sotelo, muy ducho en ingenios bélicos, cuyo mayor crédito era haber luchado en Italia con el Gran Capitán, pero el trabuco diseñado y empleado por Sotelo no funcionó. Poco después, tras ser capturado Cuauhtémoc, H. Cortés utilizó el caso de las guerras civiles entre Mario y Sila —ejemplo extraído de la lectura de La guerra de Yugurta de Salustio- para poner fin al pleito entre sus capitanes García Holguín y Sandoval, que disputaban por la captura del mexica de la misma forma como lo hicieran los caudillos romanos. Mientras que el propio Bernal Díaz intentaba comparar la mortandad habida en Tenochtitlán con la ocurrida en Jerusalén, siguiendo en este caso la obra de Flavio Josefo (Capítulo CLVI). 
Tras una exhaustiva, y por ello asombrosa, relación de los participantes en la conquista y la suerte que corrieron en el transcurso de la misma y después, Bernal Díaz reivindica no sólo la ganancia de gloria y honra mediante el ejercicio de las armas, sino también "he notado que algunos de aquellos caballeros que entonces [en el pasado] subieron a tener títulos de estados y de ilustres, no iban a las tales guerras ni entraban en batallas sin que se les diesen sueldos y salarios; y no embargante que se lo pagaban, les dieron villas y castillos y grandes tierras perpetuas, y privilegios con franquezas, los cuales tienen sus descendientes" (Capítulo CCVII). $\mathrm{Si}$ en algo se distingue el soldado de la conquista de sus correligionarios europeos es en las mercedes obtenidas aunque, con el tiempo, los motines en el Ejército de Flandes demostrarían que la vida del soldado era muy dura en todas partes.

Otros autores, por ejemplo el conocido como "El conquistador anónimo", estaban dispuestos a considerar una preparación en la conducción de la batalla entre los ejércitos del centro de México: "Guardan un cierto orden en sus guerras, pues tienen sus capitanes generales, y demás tienen otros capitanes particulares de cuatrocientos y de doscientos hombres". Poco más adelante, el mismo autor reconoce su admiración, aunque sea estética, por la formación en batalla ofrecida por los mesoamericanos, así como una cierta disciplina durante y después del combate, con duros castigos para quienes no cumplían las órdenes, o un servicio médico muy desarrollado para retirar del combate a los heridos y los muertos..$^{14} \mathrm{El}$ licenciado Jerónimo Ramírez defenderá las múltiples capacidades de los indios para, de esta forma, conseguir resaltar la victoria de Hernán Cortés. Es significativo que se escriba esta apología ante el cúmulo de opiniones que despreciaban al indio como oponente en la guerra; ahora bien, si el indio se convierte en un contrincante de talla lo fue, no tanto por sus habilidades marciales intrínsecas, que también las tenía, sino por el contacto con un enemigo superior. Utilizando ejemplos de la Antigüedad clásica — los tebanos, en principio poco dados a los asuntos marciales, terminaron siendo unos expertos en la guerra por la presión de sus contrarios-, el autor consideraba que si bien era verdad que los indios, antes del descubrimiento, "eran guerreros y belicosos, porque unas provincias con otras traían entre sí muy sangrientas guerras, poco después que pasaron a las Indias españoles y comenzaron a entrar en campo con ellos, salieron tan esforzados

14 Citado en Lameiras, José: El encuentro de la piedra y el acero, Michoacán, 1994, págs. 70-74. 
y valientes, y tan ingeniosos en ardides de milicia, que se podían comparar con los más prácticos soldados de Italia, porque los indios ni en fuerzas, ni en buena proporción y firmeza de cuerpo, ni en valor, ni en ánimo ni entendimiento, ni en discurso de razón dan la ventaja a ninguna nación del mundo". ${ }^{15}$ Y sobre los incas se tenía una opinión parecida. Pedro de Quiroga en sus Coloquios de la verdad (1563) pone en boca de Barchilón las siguientes palabras: tras comentar la increíble victoria de F. Pizarro y sus escasos hombres frente a un ejército enorme, se advierte: "Y no te engañes o no te engañen, diciendo que no eran hombres, sino indios sin razón y sin uso de guerra; porque soldados eran y muy diestros ya en la guerra y hechos a los trabajos y trances de ella, y aun soldados victoriosos que, cuando fueron acometidos de los nuestros, las lanzas traían ensangrentadas y las manos llenas de victoria de batallas que habían vencido... Al fine, era un ejército formado y armado el que los nuestros vencieron" ${ }^{16}$ Cuando el cronista Francisco de Jerez quiso comentar idéntico tema, coincidió en señalar la destreza de las tropas incaicas y su formación "en escuadras con sus banderas y capitanes que los mandan con tanto acierto como turcos". Se puede alabar militarmente al indio, pero sin compararlo con un enemigo europeo del momento: Francia o los príncipes protestantes alemanes. En cambio, la comparación con el infiel turco es factible. ${ }^{17}$

Pero, con todo, era el extraordinario número de sus guerreros su principal baza y su mentalidad bélica, más cercana a hacer prisioneros que a destruir al enemigo, su principal inconveniente. Juan Ginés de Sepúlveda, en su Historia del Nuevo Mundo, también relata la batalla de Cintla que, tras ser ganada por H. Cortés, daría lugar a la pacificación de Tabasco. Hasta 40.000 indios, divididos en cinco columnas, rodearon a la hueste hispana, de forma que, "entablado el combate, los nuestros, rodeados por tan gran número de indios, se vieron tan acosados que tuvieron que defenderse en formación cerrada". ${ }^{18}$ Aunque la caballería y los ballesteros hicieron estragos, queda clara la ventaja que suponía luchar en forma de escuadrón moderno. Francisco Cervantes de Salazar en su Crónica de la Nueva España — muy influida por F. López de Gómara- pone en boca de

15 Ramírez, Jerónimo: "Apología en defensa del ingenio y fortaleza de los indios de la Nueva España, conquistados por don Fernando Cortés, marqués del Valle", recogido en la edición de Lobo Lasso de la Vega, Gabriel: Mexicana, B.A.E., Vol. 232, Madrid, 1970, págs. 201-202.

16 Quiroga, Pedro de: Los coloquios de la verdad, Edición de Daisy Rípodas, Valladolid, 1992, pág. 80.

17 Ibídem, pág. 61.

18 Sepúlveda, Juan Ginés de: Historia del Nuevo Mundo, Madrid, 1987, pág. 102. 
H. Cortés las siguientes palabras: "Confiésoos que la gente entre quienes estamos es infinita y bien armada, pero también no me negareis que nos tienen por inmortales... Mientras más son, más se confunden y embarazan; muerto uno, van todos como los perros tras él" (tomo I, pág. 270). Para este autor el poderío militar hispano se fundamentaba en la disciplina férrea impuesta por H. Cortés y en el escuadrón. En Otumba, los indios ocupan todo el campo con su griterío, siendo descritos como "leones desatados", y se acercaban a las filas hispanas a hacer prisioneros, "pero Cortés, que vía que toda la fuerza estaba en que los suyos estuviesen juntos y en orden (...) defendió tan bien su escuadrón, que ningún soldado le llevaron" (tomo II, pág. 64). En el momento de máximo peligro, los de caballería llegaron a introducirse en el interior del escuadrón formado por los infantes para que no les matasen los caballos. Una vez superado el peligro, H. Cortés ordenó un alarde de su ejército que sirvió para animar a sus aliados indios, "encendiólos [el alarde] en un deseo ardiente de verse con los enemigos mexicanos, porque entendían que con el ayuda e favor de gente tan valiente, tan diestra y tan exercitada, no podían dexar de alcanzar victoria de sus enemigos, y envidiosos de aquel orden y manera de alarde, dixeron a Cortés que ellos querían hacer otra reseña" (tomo II, pág. 108-109). ${ }^{19}$

Las acciones militares de otro conquistador, en este caso del norte de México, Nuño Beltrán de Guzmán, también nos permiten comprobar que la lucha contra los chichimecas fue muy ardua y que, sobre todo, la formación en escuadrones al estilo practicado en Europa - especialmente en las guerras de Italia- y el uso combinado de las armas de fuego y la caballería, así como los perros, sin olvidar el concurso de los aliados indios, fue la clave del sometimiento de los naturales. Con todo, Nuño Beltrán de Guzmán quedó impresionado por la gallardía de sus contrincantes. En su invasión de lo que se llamaría la Nueva Galicia, Guzmán marchaba con sus hombres en formación, de modo que en los primeros escarceos los indios se retiraron al ver "la horden y mucha gente que llevava". Poco más adelante, el conquistador insiste en que avanzaba siempre enviando por delante ojeadores y su gente en formación, o en "horden" como él dice. Tras los primeros combates, Guzmán alaba la valentía de aquellos hombres, algunos de los cuales eran capaces de enfrentarse contra un caballero con armas de piedra y madera: "y digo esto a vuestra magestad por que se sepa que tienen ánimo muchos dellos y que osan acometer qualquier español". En

19 Cervantes de Salazar, Francisco: Crónica de la Nueva España, B.A.E., Vols. 244-245, Madrid, 1971. 
varias ocasiones, la admiración sentida hace que la comparación sólo pueda ser posible con los propios españoles: los indios peleaban "con tanto esfuerzo y ánimo como sy fueran españoles". Acostumbrados a pelear con sus semejantes, los chichimecas solían esperar a los españoles formados en batalla en lo alto de una prominencia, pero al desconocer la caballería, no pudieron prever que los caballos hispanos podían subir y atacarles. De hecho, ante esta tesitura, que se repetiría, la estrategia desarrollada por Guzmán consistía en dividir sus fuerzas en tres escuadrones: uno con toda la caballería, infantería hispana e indios aliados, que impedirían la huida del enemigo; otro compuesto por infantería hispana e indios aliados, que cubriría otro flanco y, finalmente, un tercer escuadrón, al mando del propio Guzmán, compuesto por el resto de la infantería y la artillería, cuyo cometido era el ataque frontal a la posición de los chichimecas. Los indios aliados, al comprobar la efectividad de la caballería, nunca se adelantaban si no eran acompañados por algunos caballos que los cubriesen en caso de contraataque chichimeca. En la batalla de Atecomatlán, Guzmán fue superado por la estrategia chichimeca, puesto que, de forma inconsciente, se lanzó al ataque con uno de sus tres escuadrones contra una formación india que no sólo le superaba en número, sino que fue asistida por una reserva, mientras que los otros dos escuadrones hispanos también eran atacadas simultáneamente por fuerzas superiores. De nuevo, Guzmán reconoce el "esfuerço y denuedo" de la acometida de los indios, que luchaban "con tanta destreça como sy fueran españoles, toda su vida acostunbrados en la guerra, sabiendose tan bien guardar del cavallo o de la lanza como soldados acostumbrados en aquel exerçiçio". ${ }^{20}$ En cuanto los indios exhibían una cierta disciplina y un cierto nivel estratégico, además de su arrojo, los problemas para la hueste conquistadora se incrementaban.

\section{Los tratadistas militares}

Un detalle interesante es que once tratadistas militares hispanos de los siglos XVI y XVII gozaron durante su carrera de un cargo en América. El sargento mayor Juan Márquez Cabrera, tras una dilatada carrera militar en Europa de veinte años fue enviado como gobernador y capitán general a

20 Blázquez, Adrián y Calvo, Thomas: Guadalajara y el nuevo mundo. Nuño Beltrán de Guzmán: semblanza de un conquistador, Guadalajara, 1992, las citas pertenecen a la carta enviada por Guzmán, presidente de la audiencia de México a Carlos V, 8 de julio de 1530, págs. 205-225. 
Honduras. En su obra Espejo en el que se debe mirar el buen soldado (Madrid, 1663) se refleja una cierta sensibilidad por América: su trabajo debería servir para "que ayude en algo a los soldados, asta a los de los exercitos de Europa, como a los que sirven en las dilatadas provincias y Reynos que govierna V.A.”, pero las únicas experiencias militares que valora son la europeas.

El maestre de campo - y gobernador de Gibraltar- Francisco Dávila terminó sus días como gobernador y capitán general de Cuba. Veterano de batallas como Rocroy y Lens, Francisco Dávila fue autor de dos obras Política y mecánica militar para sargento mayor de tercio (Barcelona, 1667) y Excelencias del Arte Militar y varones ilustres (Madrid, 1683) publicada póstumamente; su estancia en América, aunque activa — trabajó en las murallas de La Habana-, apenas dejó reflejo en su obra.

Diego García de Palacio, jurista de formación, aunque perteneciente a una familia de militares cántabros, desarrolló toda su carrera en el virreinato de Nueva España: oidor de la audiencia y alcalde de corte de la Ciudad de México; terminó publicando sus Diálogos militares de la formación é información de personas, instrumentos y cosas necesarias para el buen uso de la guerra en aquellas tierras (Ciudad de México, P. Ocharte, 1583).

De A. Heredia Estupiñán sólo sabemos que era hijo de militar y que estaba destinado en el virreinato del Perú, publicando en Lima (1660) una Teórica y práctica de esquadrones deducida del tesoro militar.. El autor explica muy claramente los motivos —y las circunstancias-que le impulsaron a escribir sobre estos temas: "Yo, pues, habiendo nacido hijo de sargento mayor, me incliné al formidable ministerio de los Escuadrones... A este ministerio, pues, aficionado, se aplicó mi genio en lo más florido de mi juventud, y ocupando la plaza de ayudante de mi padre fuí instruido como de mano maestra y paternal".

Juan F. Montemayor, literato y jurista, continuó su carrera iniciada en Cataluña con el cargo de magistrado en Santo Domingo, donde llegó a capitán general y, más tarde, seguiría como oidor en la audiencia de Ciudad de México. Fue autor de un apreciable Discurso político Histórico jurídico del derecho y repartimiento de presas y despojos aprehendidas en justa guerra, premios y castigos de los soldados, publicado en México (1658), que fue reeditado en Amberes en la imprenta de J. Struald en 1683 y 1685.

F. Pérez de Navarrete fue corregidor y justicia mayor del puerto de Guayaquil, en Ecuador. Fue autor de un Arte de enfrenar (Madrid, 1626) que dedicó al conde-duque de Olivares. Por su parte, el capitán Francisco 
de Céspedes y Velasco fue gobernador y capitán general de Buenos Aires y autor algunos años antes de un Tratado de la Gineta, provechosa y breve (Lisboa, Luis de Estupiñán, 1609). Dentro de este pequeño grupo de autores atraídos por la jineta y los caballos en general cabría incluir a Bernardo de Vargas Machuca; éste sirvió durante más de veinte años en Indias como maestre de campo y murió justo antes de emprender el retorno a América para servir al frente de un cargo político. Fue autor de Milicia y descripción de las Indias (Madrid, 1599) y de tres tratados sobre la jineta: Libro de exercicios de la gineta (Madrid, P. Madrigal, 1600); Teórica y exercicios de la gineta (Madrid, D. Flamenco, 1619); Compendio y doctrina nueva de la gineta... (Madrid, F. Correa de Montenegro, 1621). Y, por último, no podemos olvidarnos del único autor criollo, Juan Suárez de Peralta, y su Tratado de la caballería de la gineta y brida (Sevilla, F. Díaz, 1580). ${ }^{21}$

F. Vázquez de Silva era teniente de capitán general, corregidor y justicia mayor de Santiago de Guayaquil, en el virreinato del Perú. Su obra Fragmentos de puntos y aforismos militares y políticos, redactada en la Península, fue publicada finalmente en Lima en 1651.

El más conocido esgrimista de la segunda mitad del Quinientos, Jerónimo de Carranza, también tuvo un destino en América: fue gobernador y capitán general de Honduras. La obra que le dio fama fue Philosofia de las armas publicada a su costa en Sanlúcar de Barrameda en 1582 y reeditada en la Corte en 1600. El éxito de la esgrima en América es innegable. Se sabe que algunos criollos incluso viajaban a la Península en busca de las enseñanzas de maestros reconocidos. La polémica entre los seguidores de Carranza y los de la otra figura de la esgrima hispana, Luis Pacheco de Narváez, también tuvo su prolongación en la obra de José Mateo de Garaillana Conclusiones philosophicas de la sciencia y destreza verdadera de las armas, que inventó y sacó a la luz... G. Sánchez de Carranza (Guatemala, Antonio de Pineda, 1684). Otro esgrimista, pero de finales del Seiscientos, el maestre de campo F. Lorenz de Rada tuvo un destino como gobernador de Veracruz. Fue autor de Respuesta philosófica y matemática, en la qual se satisface a los argumentos y proposiciones que a los profesores de la verdadera destreza y philosophia de las armas... (Madrid, D. Martínez Abad, 1695) y de un Crisol de la destreza, donde se purifica el oro de la verdad (s.l., s.f.) publicado a fines del Seiscientos y, por qué no, quizás en América.

21 Sobre este autor y B. Vargas Machuca véase, Flores, Benjamín: "La jineta indiana en los textos de Juan Suárez de Peralta y Bernardo de Vargas Machuca”, Anuario de Estudios Americanos, Tomo LIV/2, 1997, págs. 639-664. 


\section{Las obras de D. García de Palacio, B. Vargas Machuca y A. Heredia}

El oidor de la Audiencia y Alcalde de Corte de la Ciudad de México, Diego García de Palacio, noble montañés, hermano de militares, escribió sus Diálogos militares... mientras estaba destinado en el virreinato de Nueva España, apareciendo en 1583. Estaba dedicado al virrey L. Suárez de Mendoza, conde de la Coruña. Eugenio de Salazar consagra una larga oda a la obra, resaltando la importancia de la artillería y las bocas de fuego en general, y sobre los escuadrones es significativo que diga: "como se abran, y cierren con presteza/ se dividan y junten los varones:/ que el orden y destreza en la batalla/ importa más, que el petto y fina malla". Ya ha pasado la época del valor personal, del ataque frontal de la caballería pesada; ahora lo que importa es el aprovechamiento técnico de la artillería, y, sobre todo, el orden en el campo de batalla impuesto por la disciplina militar. D. García de Palacio iba a descollar en la defensa de tales ideas.

Dividido en cuatro libros, el primero trata sobre las cualidades del capitán —el oficial en general- y el soldado. De entrada se pregunta si en América hay posibilidades de aprender algo en cuanto al arte de la guerra. Planteado como un diálogo entre un vizcaíno, que pregunta, y un montañés que responde, el primero habla de "la poca theórica de las cosas de la guerra que hasta ahora se ha practicado en la parte de las Indias", si lo comparamos con Italia, por ejemplo. El montañés replica que muchos de los que conquistaron las Indias ya habían aprendido el oficio en Italia antes, "y aprendieron la manera de pelear, que en particular allí es necesario: con la qual suplieron y aventajaron la que llevava o sabida... porque en las Indias

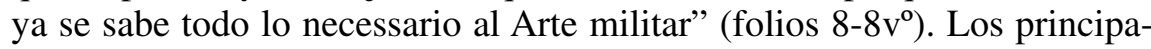
les autores citados son César, Vegecio y Tito Livio, y los ejemplos que resaltan el punto de vista del autor son extraídos de la Antigüedad clásica.

Como jurista, García de Palacio trata en primer lugar sobre la guerra justa, pero sin aportar nada nuevo al tema y, lo más interesante, tratando sobre la guerra contra los infieles, pero sin recordar las campañas de conquista contra los indios.

Según el autor, para alcanzar la victoria, que es el fin de la guerra, es necesario un cuerpo - el ejército- cuya cabeza es el general, pero debe tener un "orden y concierto" que se obtiene mediante la disciplina. D. García de Palacio aspira a hallar la formación militar perfecta, del general al soldado, sin olvidar la caballería y la artillería. El capitán ha de ser pruden- 
te y poseer fortaleza, es decir, saber escoger los medios, los momentos, etc., para hacer la guerra y disponer además de la presencia de ánimo suficiente para desarrollarlo sin decaer en su empeño. El perfil del buen capitán se complementa con buenos conocimientos de matemáticas, aritmética y cosmografía - "a lo más común he visto en los capitanes y soldados de tierra y mar, que professan esta Arte, sin el fundamento necessario de las Artes liberales" (folio 39) - . La elocuencia es útil para que el oficial incite a los soldados antes de la batalla, recordando las arengas de un César, por ejemplo.

En cuanto al soldado, es necesario que sea ante todo obediente, casto y austero; la codicia es mala compañera de las armas, "que quando Hernando Cortés tuvo preso a Mocteçuma (Señor de México), les forçaron los Indios Mexicanos a salirse y dexar la ciudad: y los que cargaron de Oro, plata y cosas preciosas, y mostraron su cobdicia: lo pagaron con la vida" (folio 47). Defendía el silencio y la concentración de las tropas en el ataque para atender las órdenes y poder los oficiales maniobrar con el escuadrón. Más que el recurso a los chillidos o cualquier otro tipo de manifestación sonora, que García de Palacio debía asimilar ahora a los indios, el enemigo debe ser impresionado con la disciplina y la pericia de las tropas formando los escuadrones. La masa de hombres en movimiento. A partir del folio 50, García de Palacio describe al recluta ideal sin poder disimular, como tantos otros tratadistas, la influencia de Vegecio. Defiende casi un imposible: que el recluta luche por la honra y no por la paga. También, la vieja idea de que el futuro soldado sea reclutado en "Provincias y partes ásperas, y de pocos regalos, donde los mancebos se crían más vellicosos, fuertes y exercitados, y que de aquella provincia se tenga experiencia de fidelidad". El ejercicio con las armas en las manos ha de ser continuo y el trabajo constante, el soldado no puede ser ocioso. Todos viejos preceptos del saber militar romano compendiado, como decíamos, por Vegecio (folios 51-55).

El libro segundo es casi una prolongación del anterior en tanto en cuanto aplica lo señalado en las diversas circunstancias de la guerra.

El libro tercero, que ocupa los folios 93-144, versa sobre las armas de fuego y la artillería, y es el que más fama ha dado al autor. Como otros muchos autores posteriores, comienza dando noticias históricas sobre la pólvora y la artillería, así como recetas particulares para fabricar pólvora de arcabuz, de cañón... Ciertamente, García de Palacio demuestra un conocimiento técnico muy grande, aunque los problemas de balística que plantea 
son muy primarios, son más bien cuestiones prácticas del tiro con arma de fuego. Trata sobre los diversos tipos de cañón, cómo cebarlos y apuntarlos y, quizás lo más novedoso, se plantea la presencia de la artillería en el mar y sus efectos sobre otras naves. ${ }^{22}$

El libro cuarto, de los folios $144 \mathrm{v}^{\circ}$ a 192 , es un arte de escuadronear típico de la época. Tras referirse a las formaciones de griegos y romanos, traza los modelos de escuadrón más usuales de su época, expone el método de la raíz cuadrada para lograr un escuadrón cuadrado perfecto — con tantos hombres de frente como de fondo- y sus variantes. Finaliza con recomendaciones sobre el lugar más aceptable para levantar un campamento y/o alojamiento de los soldados.

Hubo que esperar a 1599 para que apareciera el primer - y únicotratado militar hispano centrado en la guerra en América. El maestre de campo B. Vargas Machuca en su libro Milicia y Descripción de las Indias (Madrid, 1599) que comprende, en realidad, tres tratados, era consciente de que sus escritos podían ser de interés dispar para el lector. Vargas dirá en el prólogo que los libros "leyendo su todo no pueden dejar de dar gusto su artificio y doctrina; pero si se leen en parte, también será fuerza arrinconarse, juzgándole sin provecho". Dice B. Vargas que escribió la obra durante tres años que estuvo en la Corte reclamando alguna pretensión que tenía. Nacido en Simancas en 1555, estudió en Valladolid y, con quince años, se marchó a servir en el ejército a Italia. A su vuelta, pasó a las Indias con el cargo de maestre de campo, donde sirvió veintidós años. A su regreso a la Corte, donde permanecería, de 1599 a 1621 publicó tres libros, así como un pequeño trabajo dedicado a Felipe IV poco antes de morir en 1622: Compendio y doctrina nueva de la Gineta (Madrid, 1621). Según Nicolás Antonio, dejó inédita una "Defensa de la conquista de las Indias" en la que impugnaba la obra de Fr. Bartolomé de las Casas Brevísima relación de la

22 Al respecto, véase la obra de García de Palacio, Diego: Instrucción náutica para el buen uso y regimiento de las naos, su traza y gobierno conforme a la altura de México (Ciudad de México, P. Ocharte, 1587). La aportación sobre la artillería de este autor cabe enmarcarla entre los trabajos del tratadista artillero más influyente en la España del Quinientos, el matemático Nicolò Tartaglia (c.1499. 1557) con sus obras: Nova Scientia (Venecia, 1537), el primer tratado de balística, y Quesiti e inventioni diverse (Venecia, 1546), donde proponía, en el sexto libro, la defensa de las fortificaciones en base al fuego artillero disparado desde unas murallas de nueva planta. En ambas obras, N. Tartaglia utiliza el diálogo entre el científico sin experiencia práctica —el matemático- y el soldado práctico sin conocimientos técnicos —el artillero-. Es una relación dialéctica entre el saber abstracto que anhela una demostración empírica y el ansia por comprender el por qué del artillero. Las ideas de N. Tartaglia sobre la progresión del proyectil y el alcance de las piezas fueron refutadas a fines del XVI por autores hispanos como Alaba, Diego de: El perfecto capitán, instruido en la disciplina militar, y nueva ciencia de la artillería (Madrid, 1590) o Collado, L.: La Plática manuale (Milán, 1586). 
destrucción de las Indias (Sevilla, 1552). Fr. A. Remesal creía que no se publicó por la dureza del ataque contra Las Casas. ${ }^{23}$

Las motivaciones del autor para escribir esta obra eran claras: "la principal fue servir a la Majestad real alentando aquella milicia que tan dejativa está, y también dar escuela della a muchos caudillos que en aquellas partes emprenden conquistas y pacificaciones sin ningún conocimiento, que son causa de que se pierdan mal nuestros españoles no quedando ellos ganados. Obligóme así mismo el afición que a ésta arte de la milicia he tenido desde el día que ceñí espada, siguiéndola en Italia, armadas y en Indias".

En la aprobación de D. Juan de Mendoza, se dice que Milicia y descripción de las Indias se debe imprimir "por la mucha utilidad que causará a todas las Indias, siendo tan buen espejo para los que la dicha milicia de ellos se ocuparen, y en estas partes, por la curiosidad y cosas notables que contiene". Cuando se dirige a P. Laguna, presidente por aquel entonces del Consejo de Indias, Vargas busca que "ampare y favorezca este trabajo... abriendo a unos el camino de teórica y a otros de práctica de que carecen los más que gobiernan, así en paz como en guerra", para que tengan recopilado en forma de libro todo el conocimiento sobre la materia. También B. Vargas Machuca contó en Milicia y descripción de las Indias nueve sonetos laudatorios de oficiales y licenciados, pero destacamos otra composición del licenciado A. de Carvajal, titulada "Epístola persuasoria", en la que se puede leer: "sacando del ingenio y la experiencia/ Re militar, que es nueva y necesaria/ Las armas y la pluma tomaron vuelo,/ el ingenio y el brazo han hecho liga,/ el sabio que leyere, vaya a tiento,/ que el valor con prudencia vuela alto,/ y el que repruebe en Indias este ejercicio, /mire que pierde el nombre de soldado".

B. Vargas Machuca comienza por referir cómo las armas europeas se hubieron de adaptar a las condiciones propias de América, sustituyendo las armas defensivas de acero por otras de algodón tupido típicas de los indios de Nueva España - "En las Indias usaron al principio ballestas, cotas y corazas y pocos arcabuces, también rodelas. Ya ahora en este tiempo, con la larga experiencia, reconociendo la mejor arma y más provechosa, usan escopetas, sayos de armas hechos de algodón, espadas anchicortas, antipa-

23 Vargas Machuca, Bernardo: Milicia y descripción de las Indias, Madrid, 1892, 2 Vols. La obra en cuestión se titulaba Apologías y discursos de las conquistas occidentales (1612) y fue finalmente publicada por Fabié, A. M.: Vida y escritos de Las Casas, Madrid, 1879, tomo II, págs. 409-517. Véase al respecto, García, Ricardo: La leyenda negra, Madrid, 1992, pág. 247, nota 21 y la moderna edición de Apología y discursos de las Conquistas Occidentales, edición y estudio de María Luisa Martínez de Salinas, Avila, 1993. 
ras y morriones del dicho algodón y rodelas". Las noticias sobre las características bélicas de los indios ocupan las primeras páginas y, seguidamente, se trata de las virtudes marciales que ha de poseer el oficial - ser experimentado en asuntos de la guerra, prudente al acometer las empresas, diligente al ejecutarlas, ser diestro en el manejo del escuadrón y en la forma de gobernar las tropas-, que en las Indias, por las características de la hueste indiana, son más importantes que en la propia Europa. B. Vargas no utiliza los términos oficial o capitán, sino que emplea la palabra caudillo para referirse al jefe de guerra hispano en América. Piensa Vargas que en las Indias no se ha acertado con el tipo de personas elegidas como oficiales por los gobernadores, de modo que hay poca gente de calidad - hidalgos- entre la oficialidad... El problema es que el caudillo ha de tener un cierto caudal para mantener a sus hombres hasta que se obtenga algún botín y para pagar los gastos de una nueva conquista.

B. Vargas recomienda una cierta edad, entre 30 y 50 años, para el caudillo debido a lo trabajoso que es la conquista en América a nivel físico; pero no es menos importante la moral, la diligencia para superar todas las pruebas sin rendirse. También se ha de ser prudente - y determinado- en todas sus decisiones y contar con las opiniones de los soldados más experimentados — baquianos-. A diferencia de García de Palacio, Vargas Machuca es capaz de poner al nivel de Alejandro o César a gentes como H. Cortés, F. Pizarro o G. Jiménez de Quesada, cuyos hechos de armas le sirven de ejemplo. ${ }^{24}$

El libro segundo versa sobre las características del soldado participante en la conquista de América. Acreditar experiencia en los asuntos americanos se valoraba muchísimo, pero también un buen estado físico - tener de 15 a 50 años, no estar obeso-, de temperamento tranquilo, para no alborotar los ánimos, de modo que Vargas aconseja no llevar mujeres en las jornadas de conquista y, sí, en cambio, sacerdotes — siempre y cuando puedan seguir aquellos "trabajos"- que procuren adoctrinar a los soldados, impidiendo que blasfemen, y que adoctrinen a los indios cuando sea el caso. En las expediciones americanas era especialmente importante contar con una buena provisión no sólo de armas, municiones y herramientas —difíciles de sustituir allí—, sino también de bastimentos y, sobre todo,

24 G. Botero en su La razón de Estado no entendía que los mismos que rebajaban las proezas de los españoles en el Nuevo Mundo, "celebren las proezas de los atenienses contra Jerjes o de Alejandro Magno contra Darío, o las de Lúculo contra Tigrane o de Escipión contra Antíoco". Véase la traducción y edición de Stefano y García-Pelayo, pág. 174. 
medicinas y gente práctica que sepa curar las enfermedades, especialmente las heridas envenenadas, típicas de aquellas tierras. El ejercicio continuo con las armas es fundamental — "el soldado que fuera enemigo de cargar las armas, se puede presumir pondrá la esperanza de su vida más en los piés que en las manos" (págs. 146-147)—, pero también el conocimiento práctico; por ello, Vargas Machuca alecciona sobre el hábito de los indios de planear emboscadas y atacar en grupos reducidos, casi sin plantear nunca batallas campales, de modo que el uso de los perros que los aterroriza y, sobre todo, su capacidad para detectar las emboscadas, hace que sean insustituibles en el modo de hacer la guerra en las Indias. ${ }^{25}$

El libro tercero trata de las obligaciones generales del soldado que sirve en América — que son las mismas que en Europa—: humildad, obediencia, práctico con las armas, honrado, buen camarada, leal con el rey, honesto, buen cristiano... y cómo ha de procurar mantener la compostura en las tierras de los indios amigos; también plantea las peculiaridades de las marchas por territorio enemigo, avanzando poco a poco, haciendo continuas paradas, pero manteniendo siempre la formación de combate, las mechas encendidas y en silencio para oír antes a un enemigo que se caracteriza por el uso de lo sonoro en la guerra. Siempre hay que reconocer los caminos, o abrirlos, pero avanzando siempre con precaución. Dedica especial atención al vadeo de los ríos, que siempre es una operación militar delicada, aconsejando sobre la construcción de puentes de campaña. También ofrece consejos útiles de cómo acampar con la máxima seguridad posible y elegir tanto los días de lluvia como la noche - "trasnochada" o "encamisada"- para atacar a los indios, así como usar emboscadas con ellos, lo que nos hace pensar que Vargas Machuca analizó muy bien, y adaptó, algunas peculiaridades bélicas de los indios, pero sin admirar ninguno de sus logros. De todas formas, en Europa también se organizaban encamisadas para atacar de noche el campamento del enemigo. Un consejo se nos antoja como especialmente importante: "Aviso a los soldados que no se desabriguen uno de otro, porque en esta guerra un soldado no es más de para un indio, porque si le cogen dos indios le matarán; y si dos se hallan juntos, son pocos

25 Sobre los perros, cita F. Morales Padrón el testimonio del padre Cobo: "En las primeras conquistas se ayudaron mucho de los perros en las guerras que tuvieron con los indios; porque industriados, eran utilísimos, mayormente en tierras fragosas y de bosque, donde por ser los indios gente suelta no los podían seguir los españoles. Cobraron los indios tanto miedo a estos perros de ayuda, que en la batalla que sabían que venía algún perro desmayaban y se tenían por perdidos. Y los perros, con el artificio de la guerra y despedazar indios, se hacían bravos como tigres". Morales Padrón, Francisco: Los conquistadores de América, Madrid, 1974, pág. 115. 
veinte indios y si cuatro, son poco ciento". Siempre respetar la formación, el apoyo mutuo, la principal arma hispana. Sólo cuando el indio, como los araucanos, consigue levantar un escuadrón bien formado de picas, el hispano se verá obligado a deshacerlo con su arcabucería para, a posteriori, intentar romperlo con la caballería. ${ }^{26}$

El libro cuarto plantea cómo hacer la paz con los indios y su principal consecuencia que es la urbanización inmediata de la zona y el reparto de tierras entre los hombres... Lo mejor es mantener al indio contento con el dominio hispano, ganándose su voluntad, pero también cumpliendo siempre con lo pactado con ellos. El premio a todo soldado es inexcusable, pero mucho más al que ha servido en la conquista americana por todo lo que se ha padecido.

La obra se completaba con un tratado de la esfera y una descripción de las Indias que, junto con las obras dedicadas a la caballería de la jineta, cubren el universo de los intereses del autor.

En 1660 publicaba en Lima el sargento mayor Antonio de Heredia Estupiñán su Teórica y práctica de escuadrones. La obra se dedica al virrey del Perú, conde de Alva de Aliste. En la aprobación del capitán Juan de Leyva, éste comenta que tras una de las victorias del famoso conde de Fuentes, la batalla de Dorlan, el gobernador de la plaza Hernán Tello Portocarrero le presentó un libro de escuadrones — que no se llegaría a publicar, por lo que sabemos- y en la aprobación que del mismo hizo el sargento mayor Martín Durango, éste dijo que no sólo había que imprimirlo, sino "dar por precepto inviolable que ningún soldado esté sin él, y que se lea en los cuerpos de guardia". Leyva pensaba que lo mismo se debía decir del libro de Heredia Estupiñán por su erudición, brevedad y claridad. En la censura del capitán F. Ruiz Lozano, éste dice que en aquel libro "hallará el docto variedad de discursos en todas las ciencias y gran erudición en las matemáticas; el republicano una política cristiana; el bisoño una disciplina y enseñanza con que en breve tiempo se haga famoso milite; y el veterano nuevas derrotas y caminos que le conduzgan al más perfecto conocimiento y excelencia del arte de la milicia". Asegura que no ha visto en otras obras la manera de formar escuadrones circulares - "que en los autores que yo he visto, no solamente no la hallo practicada, más por ignorar el modo de formarlos, los han condenado por inútiles, lo que no hicie-

26 Según Alberto M. Salas, "la lucha en escuadrón cerrado, bien protegido y erizado de picas no es frecuente... si no es en Chile": Las armas de la conquista de América, Buenos Aires, 1986, pág. 277. Aún siendo una obra estimable, pensamos que el autor no dedica la atención suficiente al escuadrón hispano. 
ran si hubieran alcançado su verdadera fábrica, por ser la figura circular la más capaz y la más perfecta de las formas de la geometría"-, ni tampoco los triangulares y los de diversos lados. Y concluye: "Últimamente este tratado es digno de toda estimación y aprecio, mayormente quando en los tiempos presentes ay tan pocos que se apliquen en este reyno, no digo a escribir, más ni a estudiar esta facultad, ni que sepan unir en el Arte militar la parte práctica con la especulativa. Y es la mayor recomendación assí de la obra como del Autor averse serbido V. Exc. de que se le leyese todo este tratado en los ratos que le dexa libres la principal atención del gobierno".

En el prólogo, A. de Heredia Estupiñán nos informa que es hijo de sargento mayor y al cuidado de su padre se formó, de manera que comenzó a aficionarse no sólo a la facción práctica del asunto, sino también a la teórica, y quizás con demasiado ímpetu, pues escribió mucho, quizás demasiado y ahora, en el escrito que presenta, había quitado mucho de lo escrito, "pareciéndome que la cólera española no tiene sufrimiento para leer difusos y largos tratados, aunque sean de materias tan importantes". También asegura que le ha llevado mucho tiempo leer todos los autores que ha podido cuyas doctrinas él ha puesto en orden aspirando sólo a servir a su patria. Piensa que los tratados de los antiguos se hallan "muy esparcidos y dilatados, siendo los modernos más llenos de elegancia y retóricas, que de doctrina, la qual no bien se explica con términos esquisitos y realçados, a cuya causa solo sigo y copio los autores que hablan con estilo llano y natural... excluyendo las tropelías, confusiones de algunos modernos, que parece que de propósito no quieren que los entiendan, y assí se luce poco su enseñança, pues nadie aprende, y todos quieren ser maestros". En realidad, la obra que tratamos es sólo un extracto de otra mayor que tenía prevista para la imprenta —y que, al parecer, nunca publicó- titulada "Tesoro militar".

La obra está compuesta por 54 folios más un índice. Comienza, citando a Jenofonte, que el orden "es una de las cosas más útiles y convenientes", y que ha sido la mano de Dios, y no la sabiduría del rey Pirro de Epiro - como dicen algunos-, la que le dio a los hombres los escuadrones. El escuadrón "es orden, unión y compostura de alguna gente armada, en tal manera que moviéndose a esta y aquella parte formidablemente señoree la campaña por hallarse en él la defensa y ofensa necesaria" (Fol. $1 \mathrm{v}^{\circ}$ ). La firmeza del escuadrón se conseguirá cuando conste de orden, valor, destreza, agilidad y fuerza, valores que no siempre concurren a la vez. Tras presentar los diversos modelos de escuadrón de los que más adelante tratará, Heredia critica a aquellos que aseguran que el escuadrón circular no es 
práctico: en todo caso no han sabido formarlo y, por ello, no fían de él. Pero la realidad es que, en campo raso, este sistema es capaz de frenar un ataque de caballería por todos los lados a la vez, igual que es escuadrón cuadrado de gente. De hecho, recuerda que de este sistema se decía que podía avanzar siempre por el terreno sin problemas: ciertamente si lo atacan por los cuatro lados a la vez no. Heredia piensa que el escuadrón circular, una vez ejercitados los hombres, demostrará que es más fuerte que el cuadrado. Para el autor, toda la dificultad está en la falta de disciplina: los antiguos tenían tan disciplinados a sus hombres que ellos, por sí solos, sin necesidad de oficiales, eran capaces de formar un escuadrón. Sobre el escuadrón cuadrado de terreno tratan autores como C. Pérez de Exea y C. Lechuga, ${ }^{27}$ pero lo hacen de una forma tan "larga y obscura, [que] el estudiante que no está enterado de los otros principios de Aritmética, se ofusca y confunde tomando aversión al ministerio..." (Fol. 9). Precisamente por ello, dice Heredia Estupiñán, "pondré yo meramente las reglas de esquadrones, y una regla general para todas las proporciones, que al soldado curioso cosa fácil será aprender la aritmética en los muchos libros que hay della" (Fol. 9). Las siguientes páginas están destinadas a explicar las diversas reglas para formar los sucesivos tipos de escuadrón, siempre con la aritmética como principal aliada, aunque en el inicio de su obra ya había advertido que "la experiencia es la madre de la ciencia" (Fol. $\left.5 \mathrm{v}^{\circ}\right)$, de modo que se ha de practicar todo lo aprendido o, mejor aún, tras practicar las cosas es cuando se aprenden. También es consciente de que aquel tipo de enseñanza necesita de demostraciones visuales, mediante grabados, pero tiene que excusarse por no hacerlo, "porque en el lugar donde me hallo no aura quien abra de buril las estampas, y si lo hubiere, no aura caudal con que pagarlas" (Fol. 5).

Aún bien entrado el siglo XVII los referentes militares seguían siendo los ejércitos de la Antigüedad clásica ${ }^{28}$ y una cierta polémica — quizás

27 Lechuga, Cristóbal: Discurso que trata del cargo de Maestre de Campo General, y de todo lo que de derecho le toca en el Exercito (Milán, P. Malatesta, 1603); Pérez de Exea, Miguel: Preceptos militares, orden y formación de esquadrones..., (Madrid, Vda. de A. Martín, 1632). Otros tratados del momento: Barroso, Bernardino: Teórica, práctica y exemplos de guerra... (Milán, 1622); Fernández de Eyzaguirre, Sebastián: Libro de aritmética, con un tratado de las quatro formas de esquadrones mas acostumbradas en la milicia (Bruselas, 1608); Lorente Bravo, Miguel: Compendio militar, i tratado de esquadrones (Zaragoza, 1644).

28 Lo mismo ocurría en Europa. Véanse los trabajos de Kleinschmidt, Harald: "Using the Gun: Manual Drill and the Proliferation of Portable Firearms", The Journal of Military History, n. ${ }^{\circ}$ 63, 1999, págs. 601-630 y de Neill, Donald A.: "Ancestral voices: The Influence of the Ancients on the Military Thought of the Seventeenth and Eighteenth Centuries", The Journal of Military History, n. ${ }^{\circ}$ 62, 1998, págs. 487-520. 
artificial- sobre cuáles eran los mejores modelos de escuadrón posible, cuando en los ejércitos de la Monarquía Hispánica de pocos años más tarde, en lugar de preocupar tanto la formación de los escuadrones, interesaba mucho más reestablecer las voces de mando entre los oficiales del ejército, especialmente entre los sargentos, a tal grado de decadencia se había llegado en los difíciles años del reinado de Carlos II. 